\title{
Following Gluten Free Diet: Less Available, Higher Cost and Poor Nutritional Profile of Gluten-Free School Snacks
}

\author{
Amaya Oyarzún ${ }^{1}$, Talya Nakash ${ }^{1}$ Jimena Ayala ${ }^{1}$, Yalda Lucero², Magdalena Araya ${ }^{1, *}$ \\ ${ }^{1}$ Human Nutrition, Institute of Nutrition and Food Technology (INTA), University of Chile, Santiago, Chile \\ ${ }^{2}$ Department of Pediatrics, Faculty of Medicine, University of Chile, Santiago, Chile \\ *Corresponding author: maraya@inta.uchile.cl
}

Received May 10, 2015; Revised May 23, 2015; Accepted Jun 25, 2015

\begin{abstract}
Background. Celiac disease has a high prevalence globally and to date the only effective treatment is a strict gluten-free diet for life. Diet compliance is difficult due to current unhealthy eating habits and increasing overweight/obesity, especially for school age children. Objectives. To assess availability, cost and nutritional adequacy of gluten-free school snacks. Methods. Five store categories (large, regular-size and wholesale supermarkets, health food stores and corner shops) were assessed in districts representing low, middle and high socioeconomic levels. Three categories of school snacks were surveyed: dairy products (milk boxes, yogurts), cereals (in bulk, cereal bars) and baked goods (various cookies). Portions and prices were standardized and the closest gluten-containing products were matched for comparison. Availability, cost and nutritional quality (total calories, total fat, carbohydrates and sodium) were then evaluated. Results. A total of 1562 products were assessed. Gluten-free products were less available, with significant differences among the socioeconomic levels for cereals and baked goods $(\mathrm{P}<0.05)$. Also, they were more expensive than gluten-containing products. Except for cereal calories and sodium in the upper socioeconomic level, less than one third of the products available met FAO/WHO recommendations. Products meeting all 4 characteristics (total calories, total fat, carbohydrates and sodium) analyzed were $7.8 \%, 7.3 \%$ and $7.3 \%$ in the upper, middle and low socioeconomic level, respectively. Conclusions. Gluten-free dairy products, cereals and baked snacks available as snacks for school-age celiac children are fewer, with less variety and more expensive than gluten containing counterparts; the majority of them not meeting current nutritional recommendations.
\end{abstract}

Keywords: celiac disease, nutritional adequacy, availability, cost, gluten-free school snacks

Cite This Article: Amaya Oyarzún, Talya Nakash, Jimena Ayala, Yalda Lucero, and Magdalena Araya, "Following Gluten Free Diet: Less Available, Higher Cost and Poor Nutritional Profile of Gluten-Free School Snacks.” International Journal of Celiac Disease, vol. 3, no. 3 (2015): 102-107. doi: 10.12691/ijcd-3-3-3.

\section{Introduction}

Celiac disease (CD) is a condition observed only in humans. It results from the interaction of genes and the environment (gluten), with participation of the immune system and host microbiota. A complex and only partially understood damage to the small intestinal mucosa develops, which includes an inflammatory disease and autoimmune phenomena $[1,2,3]$. Today is known that its frequency is close to $1 \%$ in most of the assessed countries [4]. Increasing attention is currently given to the difficulties that pose maintaining a gluten-free diet, the only efficacious treatment of CD [5]. Compliance to a gluten-free diet results in symptom remission, histological and functional recovery of the small intestinal mucosa, and decreased risk of complications [6]. Although a gluten-free diet benefits celiac patients in many ways [7], evidence shows that expenditures increase in those who follow it $[8,9]$. Data also show that following strict gluten- free diet deteriorates significantly quality of life, an area that is poorly managed, mainly in less developed countries. Gluten is widely used in food processing and gluten contamination during the process of industrialized food production is of frequent occurrence [10]. Because these foods have poor elasticity due to the absence of gluten, other specific components are added, often resulting in increased content of fat and starch, i.e., higher in calories in comparison with their gluten-containing counterparts [11,12].

Given the changes of eating habits that modern life has introduced in western societies favoring the consumption of highly-processed foods, compliance to a strict glutenfree diet is increasingly more difficult. Most studies in this respect refer to US and European populations, but data about the situation in other areas of the world is scant, especially in those where bread and wheat based flour consumption is high. Availability and cost of gluten-free products is relevant because it may favor or hinder compliance to treatment, and lower compliance is 
associated with medical detriment of patients' condition and with psychosocial effects derived from accepting that they, willingly or unwillingly, must consume foods that may be harmful to them [13]. For the Food and Agriculture Organization of the United Nations (FAO) food security implies that "all people have physical, social and economic access to sufficient, safe and nutritious food, which meets their dietary needs and food preferences for an active and healthy life" [14]. For celiac individuals, food security refers to availability of gluten-free products in which their gluten content has been demonstrated to be lower than the cutoff. Chile is a middle income country where a public National Health Service provides health care to the population in a variety of areas [15], but lacks specific acts for $\mathrm{CD}$, including no obligation to declare the gluten content in product labels. At the same time, in Chile as in most countries in Latin America bread consumption is very high and overweight/obesity is vastly prevalent. This is especially so among school-age children, where it reaches $\sim 40 \%[16,17]$. Following WHO and
FAO's concepts, in this study we assessed the availability and cost of gluten-free snacks for school-age children and to what extent these snacks meet nutritional recommendations.

\section{Materials and Methods}

\subsection{Design}

Based on a convenience design, this study was conducted during the first semester of 2013 (fall/winter seasons) in three districts of different socioeconomic status (SES) in Santiago, Chile (Figure 1). Districts were chosen as representing low, middle and high SES levels, using the Socioeconomic Map of Chile/Distribution of the Regions of the Metropolitan Area, Santiago-Esomar Chile [18]. As an additional requirement, at least one large and one regular-size supermarket had to be present in the selected districts [19].

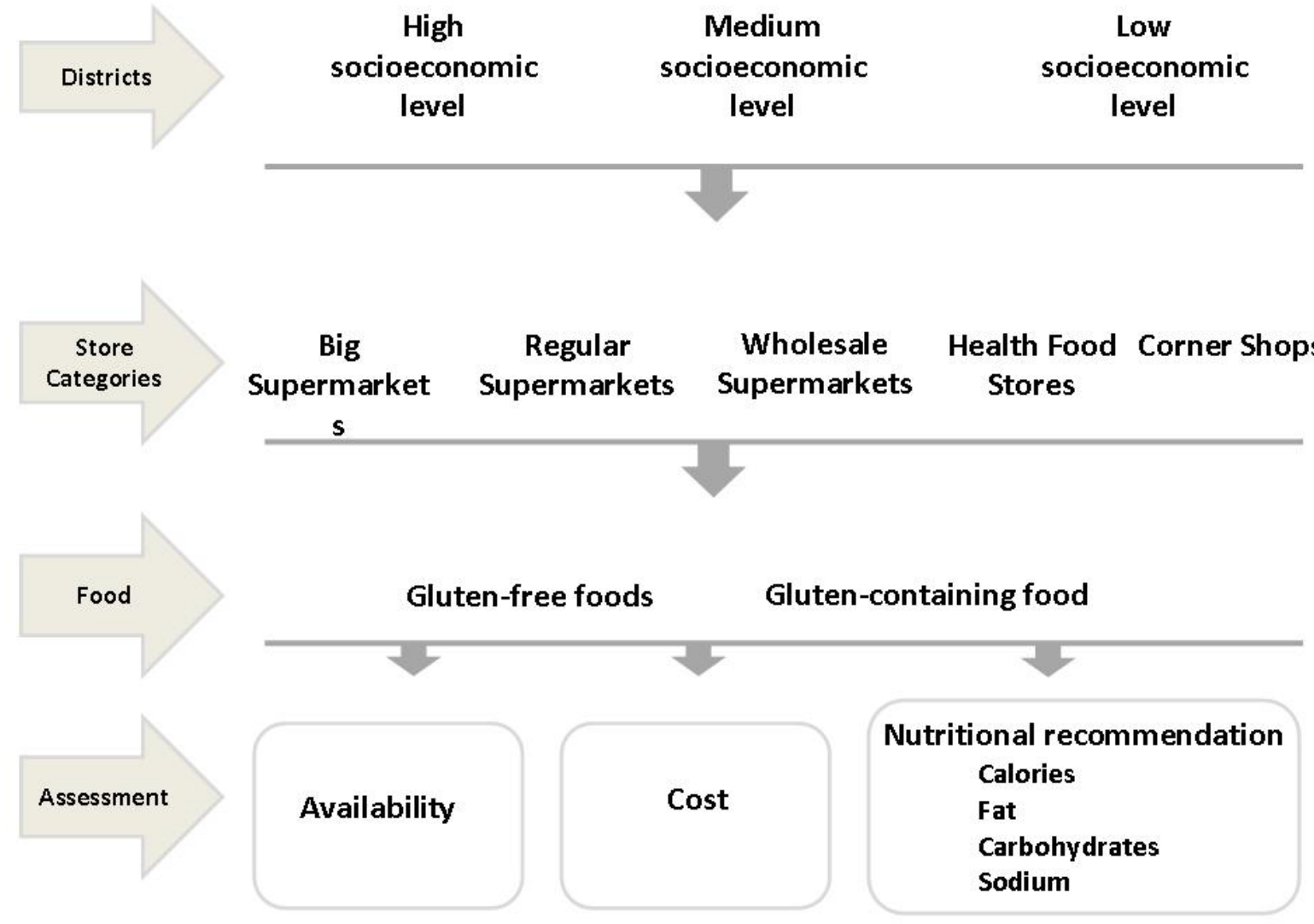

Figure 1. Algorithm

Five store categories were defined and visited (Figure 1): large supermarkets (wide variety, high quality food and high cost); regular supermarkets (wide variety and competitive cost); wholesale supermarkets (limited variety and lower cost); health food stores (containing specialized health foods); and corner shops (small, local businesses with essential products). Three categories of food were surveyed, based on current standard school snacks distributed in the country. Fruits or other natural foods were not included. Dairy products category consisted of individual milk boxes and "simple" yogurts (with no fruits or cereals added, because these were the only gluten-free yogurts available). The cereal category included cereals in bulk and cereal bars and the baked goods category consisted of various forms of crackers and cookies. In all three categories the closest gluten-containing products were matched to allow comparison with existing glutenfree equivalents, but it was clear that there was a much wider variety of more complex gluten-containing products, which could not be included because they had no glutenfree counterparts. Relevant exclusions consisted of yogurts containing fruits or other additions and cookies with various fillings and/or chocolate cover. To allow comparison, portion sizes were standardized to $200 \mathrm{ml}$ for milk, $125 \mathrm{ml}$ for yogurt, and single serving cereal bars. Cereals in bulk and individual biscuits were evaluated for a $30 \mathrm{~g}$ portion. 


\subsection{Availability}

Availability was measured following Singh and Whelan [20], registering all products with and without gluten at the given store as declared in the labels, including brand name, cost and weight/pack size.

\subsection{Cost}

Cost was recorded in Chilean pesos and then transformed into US dollars; serving sizes were also standardized such that costs could be compared.

\subsection{Nutritional Assessment of Gluten-free Products}

Nutritional information was obtained from the products labels. Total calories, total fat, carbohydrates and sodium in gluten-free snacks were documented. These data were compared with recommendations for healthy snacks set forth by the FAO/WHO [14]. For the purposes of this study we defined a healthy snack for school age children as containing no more than 130 calories, three grams of fat, 20 grams of carbohydrates per serving and no more than 140 milligrams of sodium per portion.

\subsection{Statistical Analysis}

One way Anova was used to examine differences in the availability and cost of gluten-free foods across the three socioeconomic levels, in each of the five store categories. Analyses of nutritional characteristics in the products were performed by Chi square, calculating difference between socioeconomic levels. The statistical analysis was performed using SPSS 21.0 (SPSS Inc., Chicago, IL, USA). Statistically significance was set at $\mathrm{p}<0.05$.

\section{Results}

In general, the five store categories were found in the three socioeconomic level areas, except for the low socioeconomic district, which had no health food stores. A total of 1562 products were included in the analysis. Several stores lacked some of the food items to be analyzed both for some gluten-containing and gluten-free products and this limited the analysis; in a few cases some categories resulted with zero items.

\subsection{Availability}

In the dairy products category differences between socioeconomic levels were not significant, but gluten-free dairy products were plain and of simpler formulation in comparison with their gluten-containing counterparts. The variety of gluten-free products available was lower than their gluten-containing counterparts both in the cereal and baked goods categories, in all three socioeconomic levels (Table 1). In the cereal and baked goods categories differences among socioeconomic levels were significant (one way Anova $\mathrm{P}<0.05$ ); for cereals, the main difference was seen in the large supermarket category, which had a much larger variety of gluten-containing products. In the baked goods category, only the differences in regular supermarkets was significant (one way Anova, $\mathrm{P}<0.05$ ).

Table 1. Number of gluten-containing and gluten-free products available in the five shop categories, distributed by socioeconomic level

\begin{tabular}{|c|c|c|c|c|c|c|c|c|}
\hline \multirow[b]{3}{*}{ Food categories } & \multirow[b]{3}{*}{ Shop categories } & \multicolumn{6}{|c|}{ Socioeconomic level } & \multirow[b]{3}{*}{$\mathrm{P}^{*}$} \\
\hline & & \multicolumn{2}{|c|}{ Upper } & \multicolumn{2}{|c|}{ Middle } & \multicolumn{2}{|c|}{ Lower } & \\
\hline & & With gluten & Gluten free & With gluten & Gluten free & With gluten & Gluten free & \\
\hline \multicolumn{9}{|l|}{ Dairy } \\
\hline & 1 & 38 & 14 & 28 & 10 & 29 & 11 & 0.953 \\
\hline & 2 & 35 & 9 & 25 & 9 & 27 & 10 & 0.457 \\
\hline & 3 & 30 & 10 & 24 & 9 & 23 & 8 & 0.922 \\
\hline & 4 & 0 & 0 & 0 & 0 & 0 & 0 & - \\
\hline & 5 & 0 & 4 & 10 & 4 & 9 & 4 & - \\
\hline & Total & 103 & 37 & 87 & 32 & 88 & 33 & 0.869 \\
\hline \multicolumn{9}{|l|}{ Cereals } \\
\hline & 1 & 109 & 15 & 67 & 6 & 94 & 3 & 0.014 \\
\hline & 2 & 83 & 2 & 67 & 4 & 51 & 2 & 0.578 \\
\hline & 3 & 25 & 0 & 36 & 0 & 29 & 0 & - \\
\hline & 4 & 0 & 4 & 0 & 7 & 0 & 0 & - \\
\hline & 5 & 2 & 0 & 10 & 0 & 4 & 0 & - \\
\hline & Total & 219 & 21 & 180 & 17 & 178 & 5 & 0.019 \\
\hline \multicolumn{9}{|l|}{ Baked Goods } \\
\hline & 1 & 64 & 18 & 47 & 19 & 80 & 18 & 0.500 \\
\hline & 2 & 44 & 14 & 58 & 9 & 59 & 2 & 0.001 \\
\hline & 3 & 14 & 0 & 33 & 0 & 32 & 0 & - \\
\hline & 4 & 0 & 0 & 0 & 6 & 0 & 0 & - \\
\hline & 5 & 19 & 0 & 13 & 0 & 13 & 0 & - \\
\hline Total & & 141 & 32 & 151 & 34 & 184 & 20 & 0.013 \\
\hline
\end{tabular}

One way Anova, P< 0.05. 1= Large supermarkets. 2= Regular supermarkets. 3= Wholesale supermarkets. 4= Health food stores. 5= Corner shops.

\subsection{Cost}

Gluten-free products were more expensive than glutencontaining equivalents in each food category and in all three socioeconomic levels (Table 2). There were very small differences among stores that offered the same product, while the greatest differences in costs were found among smaller shops, although this analysis was limited due to the small number of gluten-free products found in them. Dairy products appeared to be more available and with a smaller price difference in relation to glutencontaining dairy products, but it must be noted that this 
study revealed that there was only one dairy brand available that had gluten-free milk and yogurts and these products were available everywhere, a fact that reduced the possibilities of analysis. Some baked goods were $\sim 300 \%$ more expensive than their gluten-containing counterparts in the big and medium supermarkets of middle socioeconomic status (Table 2).

Table 2. Cost in dollars* of gluten containing and gluten- free products in the five shop categories, by socioeconomic level

\begin{tabular}{|c|c|c|c|c|c|c|c|c|c|c|}
\hline \multirow[b]{3}{*}{ Food categories } & \multirow[b]{3}{*}{$\begin{array}{c}\text { Shop } \\
\text { categories }\end{array}$} & \multicolumn{9}{|c|}{ Socioeconomic level } \\
\hline & & \multicolumn{3}{|c|}{ Upper } & \multicolumn{3}{|c|}{ Middle } & \multicolumn{3}{|c|}{ Lower } \\
\hline & & With gluten & Gluten- free & $\mathrm{p}$ & With gluten & Gluten- free & $\mathrm{p}$ & With gluten & Gluten- free & $\mathrm{p}$ \\
\hline & 1 & $0.48 \pm 0.10$ & $0.45 \pm 0.18$ & 0.449 & $0.46 \pm 0.10$ & $0.42 \pm 0.08$ & 0.171 & $0.47 \pm 0.11$ & $0.41 \pm 0.07$ & 0.054 \\
\hline & 2 & $0.42 \pm 0.11$ & $0.36 \pm 0.06$ & 0.127 & $0.40 \pm 0.10$ & $0.35 \pm 0.07$ & 0.244 & $0.44 \pm 0.24$ & $0.36 \pm 0.08$ & 0.295 \\
\hline & 3 & $0.49 \pm 0.15$ & $0.34 \pm 0.06$ & 0.004 & $0.40 \pm 0.11$ & $0.36 \pm 0.09$ & 0.321 & $0.39 \pm 0.11$ & $0.35 \pm 0.09$ & 0.296 \\
\hline & 4 & - & - & - & - & - & - & - & - & - \\
\hline & 5 & - & $0.61 \pm 0.00$ & - & $0.51 \pm 0.13$ & $0.45 \pm 0.08$ & 0.413 & $0.38 \pm 0.13$ & $0.39 \pm 0.09$ & 0.900 \\
\hline & Mean & $0.46 \pm 0.12$ & $0.44 \pm 0.10$ & 0.056 & $0.44 \pm 0.11$ & $0.40 \pm 0.08$ & 0.040 & $0.42 \pm 0.15$ & $0.38 \pm 0.08$ & 0.055 \\
\hline \multicolumn{11}{|l|}{ Cereals } \\
\hline & 1 & $0.36 \pm 0.24$ & $0.85 \pm 0.40$ & 0.000 & $0.42 \pm 0.27$ & $0.66 \pm 0.10$ & 0,035 & $0.35 \pm 0.22$ & $0.72 \pm 0.12$ & 0.005 \\
\hline & 2 & $0.26 \pm 0.14$ & $0.70 \pm 0.17$ & 0.000 & $0.33 \pm 0.12$ & $0.84 \pm 0.54$ & 0.000 & $0.24 \pm 0.07$ & $0.56 \pm 0.00$ & 0.000 \\
\hline & 3 & $0.49 \pm 0.12$ & - & - & $0.23 \pm 0.08$ & - & - & $0.21 \pm 0.05$ & - & - \\
\hline & 5 & $0.68 \pm 0.00$ & & - & $0.3 \pm 0.18$ & & - & $0.38 \pm 0.01$ & - & - \\
\hline & Mean & $0.45 \pm 0.12$ & $0.71 \pm 0.23$ & 0.000 & $0.34 \pm 0.16$ & $0.76 \pm 0.33$ & 0.000 & $0.30 \pm 0.09$ & $0.64 \pm 0.06$ & 0.000 \\
\hline \multicolumn{11}{|l|}{ Baked Goods } \\
\hline & 1 & $0.29 \pm 0.37$ & $0.82 \pm 0.34$ & 0.000 & $0.28 \pm 0.21$ & $0.81 \pm 0.32$ & 0.000 & $0.29 \pm 0.28$ & $0.77 \pm 0.35$ & 0.000 \\
\hline & 2 & $0.21 \pm 0.10$ & $0.81 \pm 0.50$ & 0.000 & $0.23 \pm 0.12$ & $1.13 \pm 0.49$ & 0.000 & $0.24 \pm 0.12$ & $0.65 \pm 0.18$ & 0.000 \\
\hline & 3 & $0.25 \pm 0.09$ & - & - & $0.16 \pm 0.05$ & - & - & $0.17 \pm 0.07$ & - & - \\
\hline & 4 & - & - & - & - & $1.07 \pm 0.52$ & - & - & - & - \\
\hline & 5 & $0.25 \pm 0.10$ & - & - & $0.17 \pm 0.05$ & - & - & $0.12 \pm 0.02$ & - & - \\
\hline & Mean & $0.25 \pm 0.17$ & $0.1 \pm 0.42$ & 0.000 & $0.21 \pm 0.11$ & $0.97 \pm 0.44$ & 0.000 & $0.20 \pm 0.12$ & $0.71 \pm 0.27$ & 0.000 \\
\hline
\end{tabular}

Results expressed as mean \pm SD. One way Anova, $\mathrm{P}<0.05 . *=1$ dollar $=\$ 557$ Chilean pesos. "." $=$ not found

1= Largesupermarkets. 2= Regular supermarkets. 3= Wholesale supermarkets. $4=$ Health food stores. $5=$ Corner shops.

\subsection{Nutritional Quality}

As a whole, only a small proportion of all gluten-free school snacks met nutritional recommendations (Table 3). Except for cereal calories and sodium in the upper socioeconomic level, less than one third of the products available met FAO/WHO recommendations. Products meeting all 4 features (total calories, total fat, carbohydrates and sodium) analyzed were 7.8\%, 7.3\% and $7.3 \%$ in the upper, middle and low socioeconomic status, respectively; the differences observed being always in excess of the recommendation. The poorest values were for baked goods in all three socioeconomic levels; in contrast, the best figures were in the high socioeconomic level, where imported products were more frequently available; $50 \%$ and $58.3 \%$ of the analyzed cereals in the high socioeconomic level met recommendations of calories and sodium, respectively. Although analyzing the ingredients used to produce gluten-free foods was not an objective of this study, it was noticeable that rice was the main ingredient in all baked goods identified.

Table 3. Percentage of processed gluten-free school snacks that meet nutritional requirement by FAO/WHO, shown in brackets for each individual nutrient

\begin{tabular}{|c|c|c|c|c|c|c|c|c|c|c|c|c|c|c|c|}
\hline \multicolumn{16}{|c|}{ Recommendation } \\
\hline & \multicolumn{3}{|c|}{$\begin{array}{l}\text { Calories } \\
\text { (130 kcal) }\end{array}$} & \multicolumn{3}{|c|}{$\begin{array}{l}\text { Total Fat } \\
\text { (3g) }\end{array}$} & \multicolumn{3}{|c|}{$\begin{array}{l}\text { Total Carbohydrate } \\
\text { (20g) }\end{array}$} & \multicolumn{3}{|c|}{$\begin{array}{l}\text { Sodium } \\
\text { (140mg) }\end{array}$} & \multicolumn{3}{|c|}{$\begin{array}{c}\text { All } 4 \\
\text { critical nutrients }\end{array}$} \\
\hline & $\begin{array}{l}\text { Upper } \\
\text { SEL } \\
(\%)\end{array}$ & $\begin{array}{c}\text { Middle } \\
\text { SEL } \\
(\%)\end{array}$ & $\begin{array}{l}\text { Lower } \\
\text { SEL } \\
(\%)\end{array}$ & $\begin{array}{l}\text { Upper } \\
\text { SEL } \\
(\%)\end{array}$ & $\begin{array}{c}\text { Middle } \\
\text { SEL } \\
(\%)\end{array}$ & $\begin{array}{c}\text { Lower } \\
\text { SEL } \\
(\%)\end{array}$ & $\begin{array}{l}\text { Upper } \\
\text { SEL } \\
(\%)\end{array}$ & $\begin{array}{c}\text { Middle } \\
\text { SEL } \\
(\%)\end{array}$ & $\begin{array}{l}\text { Lower } \\
\text { SEL } \\
(\%)\end{array}$ & $\begin{array}{l}\text { Upper } \\
\text { SEL } \\
(\%)\end{array}$ & $\begin{array}{c}\text { Middle } \\
\text { SEL } \\
(\%)\end{array}$ & $\begin{array}{c}\text { Lower } \\
\text { SEL } \\
(\%)\end{array}$ & $\begin{array}{l}\text { Upper } \\
\text { SEL } \\
(\%)\end{array}$ & $\begin{array}{c}\text { Middle } \\
\text { SEL } \\
(\%)\end{array}$ & $\begin{array}{c}\text { Lower } \\
\text { SEL } \\
(\%)\end{array}$ \\
\hline Food categories & & & & & & & & & & & & & & & \\
\hline Dairy (n=102) & 17.6 & 16.7 & 15.7 & 15.7 & 14.7 & 15.7 & 16.7 & 16.7 & 15.7 & 36.3 & 31.4 & 32.4 & 14.7 & 13.7 & 14.7 \\
\hline Cereals (n=36) & 50.0 & 25.0 & 13.9 & $47.2^{*}$ & $13.9^{*}$ & $8.3^{*}$ & 16.7 & 16.7 & 5.6 & 58.3 & 27.8 & 13.9 & 5.6 & 2.8 & 0.0 \\
\hline $\begin{array}{l}\text { Baked goods } \\
(\mathrm{n}=80)\end{array}$ & 23.8 & 25.0 & 21.3 & 13.8 & 16.3 & 11.3 & 16.3 & 13.8 & 10.0 & 30.0 & 27.5 & 18.8 & 0.0 & 1.3 & 1.3 \\
\hline Total $(\mathrm{n}=218)$ & 25.2 & 21.1 & 17.4 & 20.2 & 15.1 & 12.8 & 16.5 & 11.0 & 11.9 & 37.6 & 29.4 & 24.3 & 7.8 & 7.3 & 7.3 \\
\hline
\end{tabular}

\section{Discussion}

Results showed reduced availability and higher costs of gluten-free snacks, increasing the difficulties for school- age children with CD to comply with a gluten-free diet, also increasing the economic burden that celiac patients and their families face [8]. These results are relevant because at the same time the Chilean population has inadequate eating habits and white bread based on wheat 
is a main daily foodstuff, especially for lower income groups [17]. Thus, findings on baked products are relevant, especially in places with high wheat consumption as the case of Chile, where bread consumption is about $90 \mathrm{~kg}$ per person per year, among the highest globally [17]. Except for Argentine, several other countries in this geographical area also lack public health policies regulating gluten declaration in processed foods. Although this kind of data is absent in Latin America, results in general are not particularly unexpected; in Nova Scotia MacCulloch et al [21] also found that gluten-free products were fewer, more expensive and less available than their gluten-containing counterparts. Studies in Spain describe higher contents of calories, macronutrients, sodium and cholesterol in glutenfree as compared with gluten-containing foods [22]. Accessing gluten-free products may increase the amount of time spent on food shopping and reading food labels to ensure the product is safe and does not contain gluten, making shopping for food a time consuming task. Bellini et al found a relationship between people's perception of the degree to which they can control their environment (here meaning reading food labels) and compliance with a gluten-free diet [23]. For school-age children, parents are often in charge of purchasing their school snacks; while it is true that they need more time to read the labels, this may also have a positive outcome by improving parents knowledge, which can be passed to the child and encourage him/her to follow the diet.

An important finding of this study is the large proportion of products available that do not meet nutritional requirements. Today, the presence of the global pandemic of obesity and non-communicable chronic diseases (e.g. diabetes, hypertension and others) at progressively earlier ages [17] becomes a relevant factor to consider among celiac patients, a group where overweight/obesity is also increasing [17]. Indeed, celiac patients should follow current dietary recommendations and limit their intake of (saturated) fat and (added) sugar $[24,25]$. It is true that producing healthy processed glutenfree products is more difficult to accomplish, because gluten substitution often results in higher content of added sugar and fat. An alternative often offered to celiac patients is to increase naturally gluten-free foods, such as fruits and vegetables, but consumption of these is low in most western countries; in less developed countries, unavailability and higher prices are often cited as reasons that constraints eating healthier, especially in low income groups [26,27]. It seems reasonable to promote the nutritional improvement of highly processed gluten-free foods. In this study, low income areas had the poorest availability of gluten-free products and most of those present did not meet nutritional requirements.

The gluten-free products market is globally increasing, not only because the frequency of cases diagnosed with CD has increased [4], but also as a result of non-celiac groups that follow a gluten-free diet, due to wheat allergy, non-celiac gluten sensitivity or in hope of losing weight. Increased participation of these latter groups in gluten-free diets has led to a substantial increase in sales of glutenfree products [28]. Thus, it is time that gluten-free foods producers focus not only on the absence of gluten in their products, but also on their nutritional quality, paying especial attention to fiber content and the use of nonfortified raw materials.

\section{Conclusions}

This study shows that gluten-free dairy products, cereals and baked snacks available to school-age children in Santiago, Chile are fewer, less diverse and more expensive than gluten-containing products; and most importantly, the vast majority of them do not meet nutritional recommendations. These results should alert health policy planners and gluten-free producer companies that are working to improve the management of CD and patients' quality of life.

\section{References}

[1] Husby S, Koletzko S, Korponay-Szabo IR, et al. European Society for Pediatric Gastroenterology, Hepatology, and Nutrition guidelines for the diagnosis of coeliac disease. J Pediatr Gastroenterol Nutr. 2012 Jan;54:136-60.

[2] Tommasini A, Not T, Ventura A. Ages of celiac disease: from changing environment to improved diagnostics. World J Gastroenterol. 2011 Aug 28;17:3665-71.

[3] Kupfer SS, Jabri B. Pathophysiology of celiac disease. Gastrointest Endosc Clin N Am. 2012 Oct;22:639-60.

[4] Kang JY, Kang AH, Green A, et al. Systematic review: worldwide variation in the frequency of coeliac disease and changes over time. Aliment Pharmacol Ther. 2013 Aug;38:226-45.

[5] Niewinski MM. Advances in celiac disease and gluten-free diet. J Am Diet Assoc. 2008 Apr;108:661-72.

[6] Lee A, Newman JM. Celiac diet: its impact on quality of life. J Am Diet Assoc. 2003 Nov;103:1533-5.

[7] Mustalahti K, Lohiniemi S, Collin P, et al. Gluten-free diet and quality of life in patients with screen-detected celiac disease. Eff Clin Pract. 2002 May-Jun;5:105-13.

[8] Long KH, Rubio-Tapia A, Wagie AE, et al. The economics of coeliac disease: a population-based study. Aliment Pharmacol Ther. 2010 Jul;32:261-9.

[9] Catassi C, Kryszak D, Louis-Jacques O, et al. Detection of Celiac disease in primary care: a multicenter case-finding study in North America. Am J Gastroenterol. 2007 Jul;102:1454-60.

[10] Verrill L, Zhang Y, Kane R. Food label usage and reported difficulty with following a gluten-free diet among individuals in the USA with coeliac disease and those with noncoeliac gluten sensitivity. J Hum Nutr Diet. 2013 Oct;26:479-87.

[11] Shepherd SJ, Gibson PR. Nutritional inadequacies of the glutenfree diet in both recently-diagnosed and long-term patients with coeliac disease. J Hum Nutr Diet. 2013 Aug;26:349-58.

[12] Kabbani TA, Goldberg A, Kelly CP, et al. Body mass index and the risk of obesity in coeliac disease treated with the gluten-free diet. Aliment Pharmacol Ther. 2012 Mar;35:723-9.

[13] Dowd AJ, Tamminen KA, Jung ME, et al.Motives for adherence to a gluten-free diet: a qualitative investigation involving adults with coeliac disease. J Hum Nutr Diet. 2014 Dec;27:542-9.

[14] http://www.paho.org/docrep/meeting/026/me888e.pdf. 2013. Accessed March 27, 2015

[15] www.minsal.cl. Accessed March 27, 2015

[16] Rivera JA, de Cossio TG, Pedraza LS, et al. Childhood and adolescent overweight and obesity in Latin America: a systematic review. The lancet Diabetes \& endocrinology. 2014 Apr;2:321-32.

[17] Encuesta Nacional de Salud 2009-2010 (National health Survey), Departamento de Epidemiología, Ministerio de Salud de Chile. http:// www.minsal.gob.cl/portal/docs/page/minsalcl/g_home/ submenu_portada20111/ens2010.pdf. Accessed March March 27, 2015.

[18] The European Society for Marketing and Research. The ESOMAR Standard Demographic Classification. In : Hoffmeyer-Zlotnik, Wolf, eds. Advances in Cross-National Comparison. A European Working Book for Demographic and Socio-Economic Variables. New York: Academic/Plenum Publishers; 2003: pp 97-121. 2003

[19] Kinsey L, Burden ST, Bannerman E. A dietary survey to determine if patients with coeliac disease are meeting current healthy eating guidelines and how their diet compares to that of the British general population. Eur J Clin Nutr. 2008 Nov;62:1333-42. 
[20] Singh J, Whelan K. Limited availability and higher cost of glutenfree foods. J Hum Nutr Diet. 2011 Oct;24:479-86.

[21] MacCulloch K, Rashid M. Factors affecting adherence to a glutenfree diet in children with celiac disease. Paediatrics \& child health. 2014 Jun;19(6):305-9.

[22] Segura ME, Rosell CM. Chemical composition and starch digestibility of different gluten-free breads. Plant foods for human nutrition. 2011 Sep;66:224-30.

[23] Bellini A, Zanchi C, Martelossi S, et al. Compliance with the gluten-free diet: the role of locus of control in celiac disease. J Pediatr. 2011 Mar;158:463-6 e5.

[24] Revised dietary guidelines to help Americans live healthier lives. FDA consumer. 2005 Mar-Apr;39:18-9.
[25] Mozaffarian D, Hao T, Rimm EB, et al. Changes in diet and lifestyle and long-term weight gain in women and men. N Engl J Med. 2011 Jun 23;364:2392-404.

[26] Krebs-Smith SM, Kantor LS. Choose a variety of fruits and vegetables daily: understanding the complexities. J Nutr. 2001 Feb;131:487S-501S.

[27] Reicks M, Randall JL, Haynes BJ. Factors affecting consumption of fruits and vegetables by low-income families. J Am Diet Assoc. 1994 Nov;94:1309-11.

[28] Lamacchia C, Camarca A, Picascia S, et al. Cereal-based glutenfree food: how to reconcile nutritional and technological properties of wheat proteins with safety for celiac disease patients. Nutrients. 2014;6:575-90. 